\title{
A novel strategy to inhibit the reproduction and translation of hepatitis $\mathbf{C}$ virus
}

\author{
DUAN AiPing ${ }^{1}$, NING LiMin ${ }^{1}$, LI Chao ${ }^{1}, \mathrm{HOU} \mathrm{YaFei}^{2}, \mathrm{YANG} \mathrm{NaNa}^{3}$, \\ SUN LiZhou ${ }^{3} \&$ LI GenXi, ${ }^{1, *}$ \\ ${ }^{1}$ Department of Biochemistry and State Key Laboratory of Pharmaceutical Biotechnology, Nanjing University, Nanjing 210093, China; \\ ${ }^{2}$ Laboratory of Biosensing Technology, School of Life Sciences, Shanghai University, Shanghai 200444, China; \\ ${ }^{3}$ Department of Obstetrics, the First Affiliated Hospital of Nanjing Medical University, Nanjing 210036, China
}

Received February 26, 2013; accepted March 11, 2013; published online March 18, 2013

\begin{abstract}
Hepatitis C virus (HCV), a positive single-stranded RNA virus, is a major cause of liver disease in humans. Herein we report a novel strategy to inhibit the reproduction and translation of HCV using a short RNA, named an Additional RNA, to activate the endonuclease activity of Argonaute 2 (Ago2). In the presence of the Additional RNA, the HCV genome RNA has the requisite 12 nucleotides of base-pairing with microRNA-122. This activates the endonuclease activity of Ago2, resulting in cleavage and release of the HCV genome RNA from Ago2 and microRNA-122. The free HCV genome RNA would be susceptible to intracellular degradation, effectively inhibiting its reproduction and translation. This study presents a new method to inhibit HCV that may hold great potential for HCV treatment in the future.
\end{abstract}

hepatitis $\mathrm{C}$ virus, reproduction and translation, Argonaute 2 protein, electro-analysis, biosensor

Citation: Duan A P, Ning L M, Li C, et al. A novel strategy to inhibit the reproduction and translation of hepatitis C virus. Sci China Life Sci, 2013, 56: 293-297, doi: 10.1007/s11427-013-4468-2

Hepatitis $\mathrm{C}$ is an infectious disease that affects over $3 \%$ of the worldwide population, especially in developing countries. There is no vaccine against the Hepatitis $\mathrm{C}$ virus (HCV), and the currently used drugs such as PEGylated interferon $\alpha$, ribavirin, telaprevir, and boceprevir produce significant adverse effects [1-4]. Therefore, an alternative and specific therapy for HCV is desperately needed.

$\mathrm{HCV}$ is a positive single-stranded RNA virus [5,6]. For replication and translation, the HCV RNA genome needs to recruit the Argonaute 2 (Ago2) protein, one of the components of the RNA-induced silencing complex that mediates RNA silencing [7-11]. Ago2 has four domains: N, PAZ, MID, and PIWI. The PIWI domain has endonucleolytic activity and the PAZ domain binds single-stranded RNA

*Corresponding author (email: genxili@nju.edu.cn)
[12,13]. Ago2 binds to microRNA (miRNA)-122 (miR-122), which is an abundant and liver-specific miRNA that regulates the expression of numerous hepatic genes [14-17]. Meanwhile, miR-122 binds to the $5^{\prime}$ untranslated region (UTR) of the HCV genome that has two conserved seedsequence sites ( $\mathrm{S} 1$ and $\mathrm{S} 2$ ) at nucleotides 2-8 [5,14,18]. Therefore, Ago2 and miR-122 protect the viral genome from the host mRNA decay machinery [14]. Previous studies have suggested that miR-122 normally functions to regulate HCV's association with Ago2 [18]. Depletion of Ago2 may lead to a reduction in HCV RNA of more than $50 \%$, and reduce the ability of miR-122 to stimulate viral translation [7,14,18]. We hypothesized that releasing the HCV genome RNA from Ago2 and miR-122 might be an effective way to inhibit $\mathrm{HCV}$ reproduction and translation, potentially being an efficient way to treat hepatitis $\mathrm{C}$. 
We previously established a method to assay the activity of Ago2 [19]. Here, we have taken advantage of this protein's endonucleolytic activity to separate the HCV genome RNA from Ago2 and miR-122.

\section{Materials and methods}

\subsection{Materials}

Recombinant mammalian Ago2 of purity higher than 97\% was purchased from Sino Biological Inc. (Beijing, China). Nuclease inhibitor RNasin, S1 nuclease, and diethylpyrocarbonate (DEPC) were purchased from Promega (Madison, WI, USA). Tris(2-carboxyethyl)phosphine hydrochloride, 6-mercapto-1-hexanol, hydrogen peroxide solution (30\% $\mathrm{H}_{2} \mathrm{O}_{2}$ ), sulfuric acid were ordered from Sigma-Aldrich (St. Louis, MO, USA). All other reagents were of analytical reagent grade and used as received. P5000 silicon carbide paper and alumina powder were purchased from Gaoss Union (Wuhan, China).

Oligonucleotides were synthesized and purified by TaKaRa Biotechnology Co., Ltd. (Dalian, China). The sequences of the oligonucleotides used were as follows: miR-122: 5'-UGGAGUGUGACAAUGGUGUUUGU-3' [6, 18,20,21]; HCV 5' UTR: 5'-ACACUCCACCAUGA-SH-3'; simulated cleaved HCV 5' UTR: 5'-ACUCCACCAUGA-SH3'; Additional RNA: 5'-CCAUUGUC-3'; methylene blue (MB)-labeled DNA: 5'-TCATGGTGGAGTGT-MB-3'.

The buffer solutions used were as follows. Stock solution for oligonucleotides: $0.1 \mathrm{mmol} \mathrm{L}{ }^{-1}$ phosphate-buffered saline (PBS) (pH 7.4) containing 1\% DEPC; RNA immobilization solution: $10 \mathrm{mmol} \mathrm{L}^{-1}$ Tris- $\mathrm{HCl}$ containing $10 \mathrm{mmol} \mathrm{L}^{-1}$ Tris(2-carboxyethyl)phosphine hydrochloride, $0.1 \mathrm{~mol} \mathrm{~L}^{-1}$ EDTA, and 1\%o DEPC (pH 7.4); Ago2 binding buffer: 20 mmol L ${ }^{-1}$ Tris- $\mathrm{HCl}$ containing 1 unit $\mu \mathrm{L}^{-1} \mathrm{RNasin}, 50 \mathrm{mmol}$

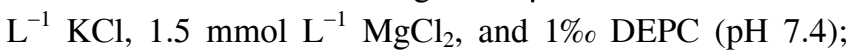
hybridization buffer: $1 \times$ saline sodium citrate [22]; detection buffer: $20 \mathrm{mmol} \mathrm{L}{ }^{-1}$ PBS ( $\mathrm{pH} 7.0$ ). All solutions were prepared with double-distilled water that was purified with a Milli-Q purification system (Barnstead, Iowa, USA) to a specific resistance of $>18 \mathrm{M} \Omega \mathrm{cm}$.

\subsection{Cleavage of HCV 5' UTR by Ago2}

Ago2 protein was diluted to $25 \mathrm{nmol} \mathrm{L}^{-1}$ with Ago2 binding buffer and preincubated with $1 \mu \mathrm{mol} \mathrm{L}{ }^{-1} \operatorname{miR}-122$ at $37^{\circ} \mathrm{C}$ for $30 \mathrm{~min}$, forming the Ago2-miRNA complex [19]. Then, HCV 5' UTR and the indicated concentration of Additional RNA were added, and hybridized with miR-122 after incubating at $37^{\circ} \mathrm{C}$ for $1 \mathrm{~h}$. The complex comprising the HCV 5' UTR, Additional RNA, and miR-122 activates the endonuclease activity of Ago2, resulting in cleavage of the HCV 5' UTR.

\subsection{Preparation of HCV 5' UTR-modified electrode}

The HCV 5' UTR was modified with thiol so it could be immobilized onto a gold electrode surface via gold-sulfur chemistry. Before immobilization, the electrode $(3 \mathrm{~mm}$ in diameter) was soaked in piranha solution $(70 \%$ concentrated sulfuric acid, $30 \% \mathrm{H}_{2} \mathrm{O}_{2}$ ) for $15 \mathrm{~min}$. Then, it was polished carefully with P5000 silicon carbide paper and a microcloth with $1.0-, 0.3-$, then $0.05-\mu \mathrm{m}$ alumina powder. After that, the electrode was sonicated in ethanol then double-distilled water for $5 \mathrm{~min}$ each. Finally, the electrode was soaked in $50 \%$ hydrogen nitrate for $30 \mathrm{~min}$, followed by electrochemical activation in $0.5 \mathrm{~mol} \mathrm{~L}^{-1} \mathrm{H}_{2} \mathrm{SO}_{4}$ to remove any remaining impurities. After being dried with nitrogen, the electrode was incubated with the HCV 5' UTR for $12 \mathrm{~h}$ at $4^{\circ} \mathrm{C}$ to form a self-assembled monolayer of the HCV 5' UTR on the electrode surface. Following a 1-h treatment with $1 \mathrm{mmol}$ $\mathrm{L}^{-1}$ 6-mercapto-1-hexanol, the electrode was rinsed with double-distilled water containing $1 \%$ DEPC. It was then ready for further experiments.

\subsection{Assay of Ago2 endonuclease activity activated by Additional RNA}

MB-labeled DNA was employed as an electrochemical probe. After modification of the electrode with the HCV 5' UTR, it was immersed in $1 \mu \mathrm{mol} \mathrm{L}{ }^{-1}$ MB-labeled DNA for $2.5 \mathrm{~h}$ at room temperature for hybridization. Then, 0.2 unit $\mu \mathrm{L}^{-1}$ of $\mathrm{S} 1$ nuclease was added to hydrolyze unpaired DNA strands. The cleavage was allowed to proceed for $1 \mathrm{~h}$ at $25^{\circ} \mathrm{C}$. Then, the electrode was rinsed with double-distilled water containing $1 \%$ DEPC. It was then ready to be used for the following electrochemical measurements.

\subsection{Electrochemical measurements}

Cyclic voltammetry (CV) and differential pulse voltammetry (DPV) were performed on a model 430A electrochemical analyzer (CH Instruments, Shanghai, China) at room temperature with a three-electrode system consisting of the modified gold electrode as the working electrode, a platinum auxiliary electrode, and a saturated calomel as the reference electrode. CV and DPV were carried out in PBS with a scan range from -0.05 to $-0.45 \mathrm{~V}$.

\section{Results}

\subsection{Activation of Ago2 endonuclease activity with Ad- ditional RNA}

The detailed mechanism of our strategy is as follows. The endonuclease activity of Ago2 requires nucleotides 9-12 of base-pairing between an miRNA and its target mRNA; Ago2 then cleaves the mRNA between the 10th and 11th 
based-paired nucleotides [23]. However, the seed sequence in the viral 5' UTR of HCV, which binds to miR-122, is less than 12 nucleotides long, meaning that Ago2 has no endonuclease activity for $\mathrm{HCV}$. We proposed to introduce a short piece of RNA, named an 'Additional RNA', to activate the endonuclease activity of Ago2. Specifically, when the Additional RNA binds to miR-122, it can form $12 \mathrm{nu}$ cleotides of base-pairing with the HCV 5' UTR, thus activating the endonuclease activity of Ago2. When Ago2 cleaves the HCV 5' UTR, the latter is released from Ago2 and miR-122; thus, the protection of the viral genome is removed and the RNA will be degraded, effectively inhibiting reproduction and translation of $\mathrm{HCV}$. Therefore, as illustrated in Figure 1, first, Ago2 is preincubated with miR-122 to allow the miRNA to bind to Ago2, forming Ago2-miRNA complexes. Then, the HCV 5' UTR and the Additional RNA are separately added. Both will hybridize to miR-122 with a nick between them. This hybridization activates the endonuclease activity of Ago2 and results in cleavage of the $5^{\prime}$ end of the HCV 5' UTR.

\subsection{An electrochemical biosensor to detect cleaved HCV 5' UTR}

To assay the cleavage of the HCV 5' UTR by Ago2, we designed an electrochemical biosensor. This biosensor is fabricated with S1 nuclease, which hydrolyzes singlestranded regions in DNA-RNA hybrids [24]. As illustrated in Figure 2, a gold electrode is immobilized with cleaved HCV 5' UTR through the Au-S bond. Then, the electrode is immersed in MB-labeled DNA. The MB-labeled DNA is complementary to the cleaved HCV $5^{\prime}$ UTR, but is 2 bp longer than it, such that when they hybridize, 2 bp remains unpaired. When S1 nuclease is added, the unpaired DNA will be hydrolyzed, thus releasing the labeled electrochemical probe, MB. Accordingly, no electrochemical signal can be obtained. If the HCV 5' UTR is not cleaved, there is no unpaired MB-labeled DNA, S1 nuclease has no effect, and an electrochemical signal can be obtained.

\subsection{Evidence of HCV 5' UTR cleavage measured by CV}

$\mathrm{CV}$ is an efficient tool to investigate the behavior of the surface of an electrode. We used this technique to measure whether the Additional RNA resulted in a different electrochemical response of the HCV 5' UTR-modified electrode. When the Additional RNA was present, nearly no peak could be observed (Figure 3A). In the absence of Additional RNA, there is thus no digestion of unpaired nucleic acids by

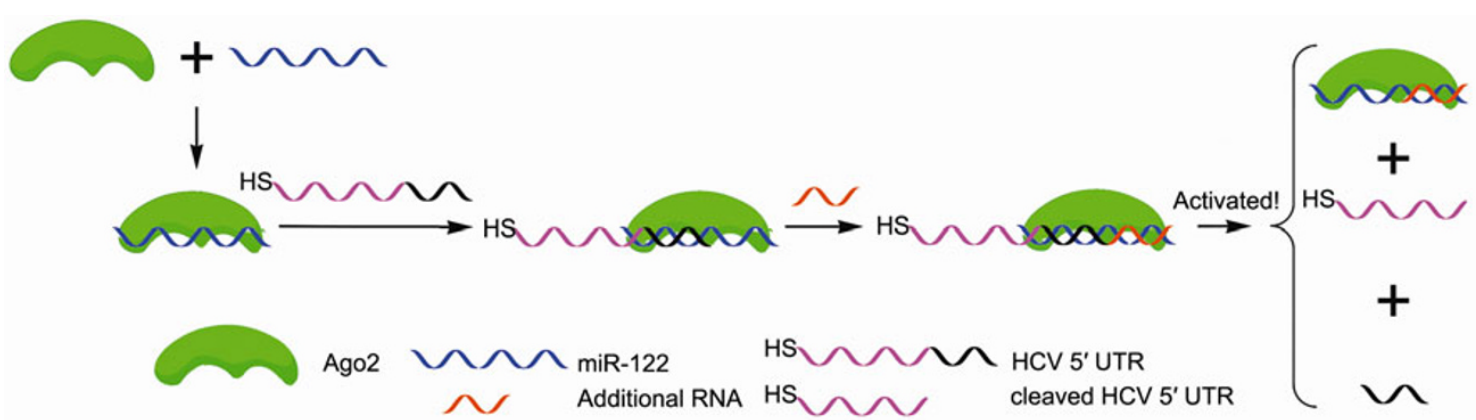

Figure 1 Schematic of the strategy to inhibit HCV reproduction and translation by activating the endonuclease activity of Ago2 with an Additional RNA.

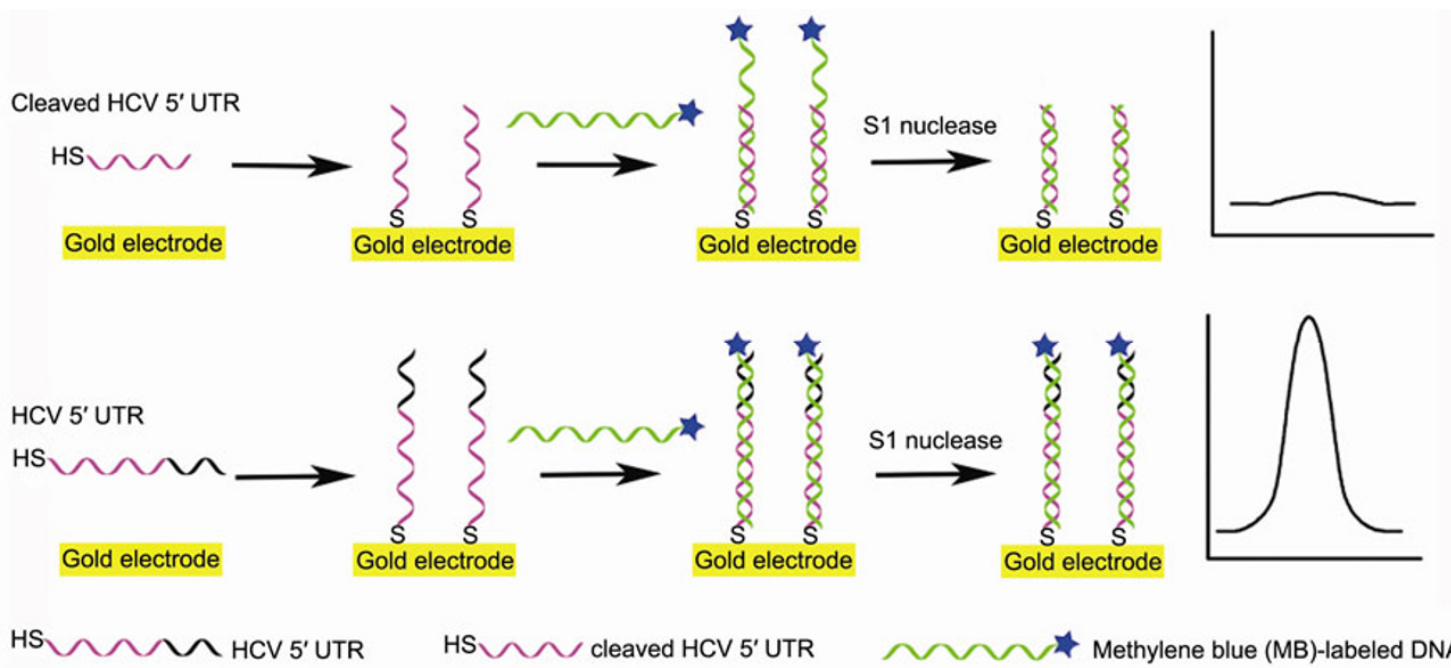

Figure 2 Schematic illustration of the electrochemical detection of the cleaved HCV $5^{\prime}$ UTR. 
S1 nuclease and a pair of typical reduction and oxidation peaks for MB can be observed (Figure 3B).

\subsection{More evidence of HCV 5' UTR cleavage obtained by DPV}

We also used DPV in our assay, because this technique can be more accurate and sensitive than $\mathrm{CV}$ at measuring the change in an electrode surface. Figure 4 depicts DPV data for different concentrations of Additional RNA. The peak current decreased with increasing Additional RNA in the range $0-2 \mu \mathrm{mol} \mathrm{L}^{-1}$, indicating a dose-response relationship.
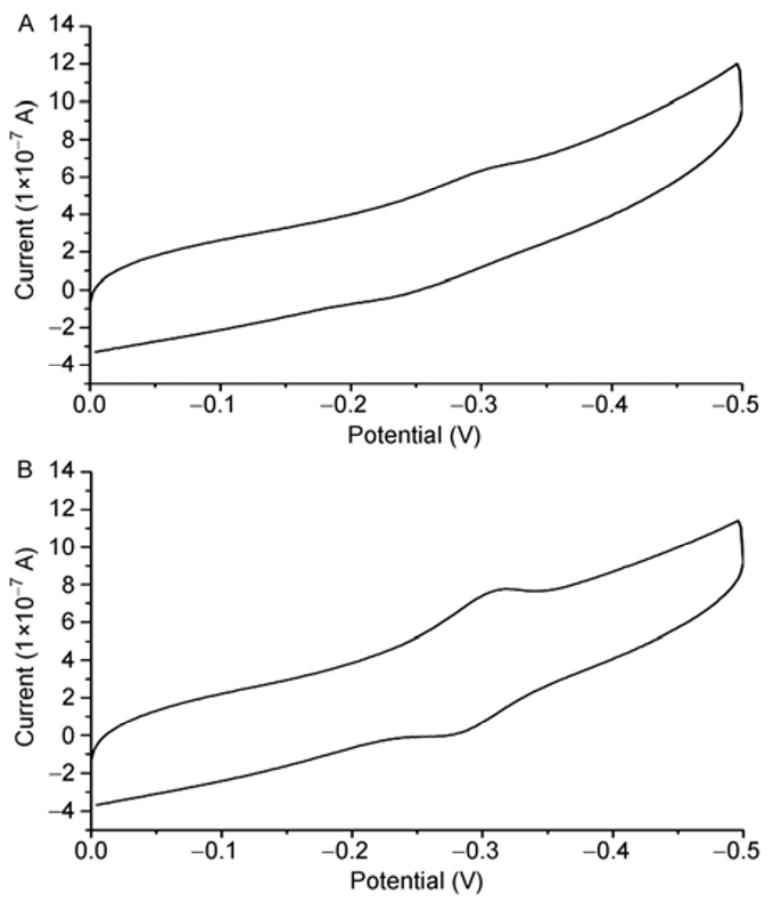

Figure 3 Cyclic voltammogram obtained at the HCV 5' UTR-modified electrode with (A) and without (B) the addition of $2 \mu \mathrm{mol} \mathrm{L} \mathrm{L}^{-1}$ Additional RNA. Scan rate, $100 \mathrm{mV} \mathrm{s}^{-1}$.

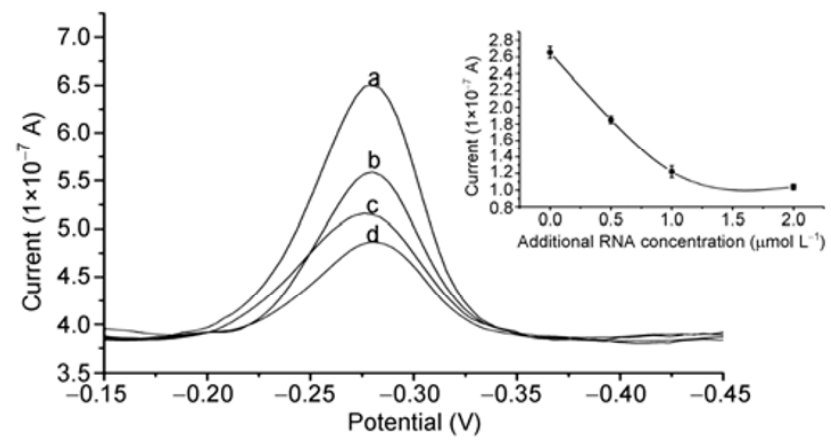

Figure 4 Differential pulse voltammograms obtained at the HCV 5 UTR-modified gold electrode for different concentrations of Additional RNA. Curves a-d correspond to a concentration of $0,0.5,1$, and $2 \mu \mathrm{mol}$ $\mathrm{L}^{-1}$ Additional RNA, respectively. The inset shows the relationship between the peak current and the concentration of Additional RNA.

\subsection{Confirmation with a simulated cleaved HCV 5' UTR}

To confirm that our biosensor is indeed detecting cleaved HCV 5' UTR, we used a simulated cleaved HCV 5' UTR, whose sequence was the same as that of the cleaved HCV $5^{\prime}$ UTR produced by Ago2. For comparison, the simulated cleaved HCV 5' UTR and the HCV 5' UTR were separately immobilized on the surface of the working electrode. As shown in Figure 5, the peak current obtained at the simulated cleaved HCV 5' UTR-modified electrode (curve b) was much lower than that at the HCV $5^{\prime}$ UTR-modified electrode (curve a). Moreover, the peak current for HCV 5' UTR in the presence of $2 \mu \mathrm{mol} \mathrm{L}{ }^{-1}$ Additional RNA (curve c) -when nearly all molecules were cleaved-was almost identical to that observed for the simulated HCV $5^{\prime}$ UTR (curve b). This confirms that the Additional RNA does indeed activate Ago2 to cleave the HCV 5' UTR.

\section{Discussion}

There is no vaccine for HCV, and the currently used drugs have very limited efficacy and significant adverse effects. In this study, we describe an alternative method to inhibit $\mathrm{HCV}$ that holds great promise for future HCV treatment. By adding a short Additional RNA, we promoted Ago2-mediated cleavage of the HCV 5' UTR, which, in vivo, would leave the viral genome prone to intracellular degradation. Our custom electrochemical biosensor provides a novel and effective way to detect the cleavage.

Our idea and experimental results are similar to RNA interference. Therefore, the introduction of an Additional RNA to activate Ago2 and promote target mRNA cleavage may provide another pathway for RNA interference.

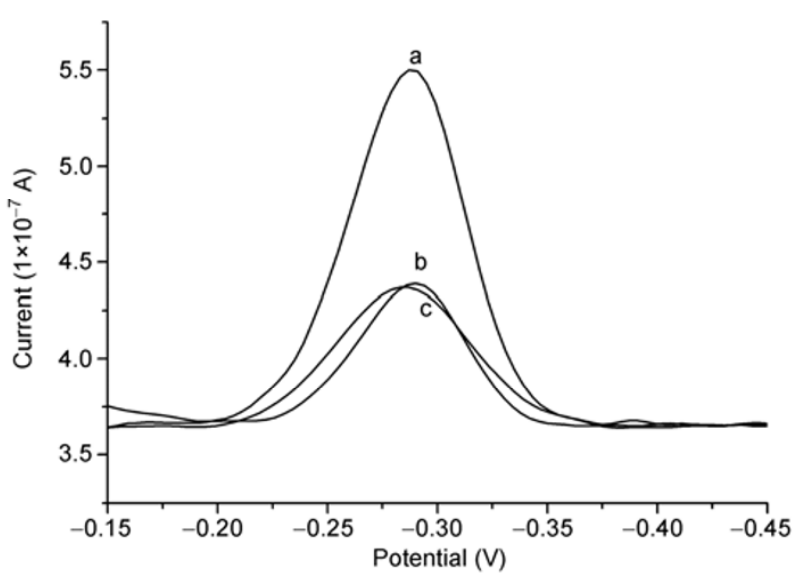

Figure 5 Differential pulse voltammograms obtained with (a and c) the HCV 5' UTR- and (b) the simulated cleaved HCV 5' UTR-modified gold electrode. In (c), $2 \mu \mathrm{mol} \mathrm{L} \mathrm{L}^{-1}$ of Additional RNA was added, such that nearly all the molecules were cleaved. 
This work was supported by the National Science Fund for Distinguished Young Scholars (20925520), the National Natural Science Foundation of China (21235003), and the Leading Academic Discipline Project of Shanghai Municipal Education Commission (J50108).

1 Khaliq S, Jahan S, Ijaz B, et al. Inhibition of hepatitis C virus genotype 3 a by siRNAs targeting envelope genes. Arch Virol, 2011, 156: 433-442

2 Chevalier C, Saulnier A, Benureau Y, et al. Inhibition of hepatitis C virus infection in cell culture by small interfering RNAs. Mol Ther, 2007, 15: 1452-1462

3 Chang B, Lee $\mathrm{C} \mathrm{H}$, Lee $\mathrm{J} \mathrm{H}$, et al. Comparative analysis of intracellular inhibition of hepatitis $\mathrm{C}$ virus replication by small interfering RNAs. Biotechnol Lett, 2010, 32: 1231-1237

4 Clark V C, Peter J A, Nelson D R. New therapeutic strategies in HCV: second-generation protease inhibitors. Liver Int, 2013, 33(Suppl 1): 80-84

5 Ariumi Y, Kuroki M, Kushima Y, et al. Hepatitis C virus hijacks P-body and stress granule components around lipid droplets. J Virol, 2011, 85: 6882-6892

6 Jopling C L, Schutz S, Sarnow P. Position-dependent function for a tandem microRNA miR-122-binding site located in the hepatitis $\mathrm{C}$ virus RNA genome. Cell Host Microbe, 2008, 4: 77-85

7 Berezhna S Y, Supekova L, Sever M J, et al. Dual regulation of hepatitis C viral RNA by cellular RNAi requires partitioning of Ago2 to lipid droplets and P-bodies. RNA, 2011, 17: 1831-1845

8 Liu J, Carmell M A, Rivas F V, et al. Argonaute2 is the catalytic engine of mammalian RNAi. Science, 2004, 305: 1437-1441

9 Tan G S, Garchow B G, Liu X, et al. Expanded RNA-binding activities of mammalian Argonaute 2. Nucleic Acids Res, 2009, 37: 75337545

10 Rand T A, Ginalski K, Grishin N V, et al. Biochemical identification of Argonaute 2 as the sole protein required for RNA-induced silencing complex activity. Proc Natl Acad Sci USA, 2004, 101: 1438514389

11 Liu Y, Tan H, Tian H, et al. Autoantigen La promotes efficient RNAi, antiviral response, and transposon silencing by facilitating multiple- turnover RISC catalysis. Mol Cell, 2011, 44: 502-508

12 Schirle N T, MacRae I J. The crystal structure of human Argonaute2. Science, 2012, 336: 1037-1040

13 Voinnet O. Origin, biogenesis, and activity of plant microRNAs. Cell, 2009, 136: 669-687

14 Shimakami T, Yamane D, Jangra R K, et al. Stabilization of hepatitis $\mathrm{C}$ virus RNA by an Ago2-miR-122 complex. Proc Natl Acad Sci USA, 2012, 109: 941-946

15 Young D D, Connelly C M, Grohmann C, et al. Small molecule modifiers of microRNA miR-122 function for the treatment of hepatitis $\mathrm{C}$ virus infection and hepatocellular carcinoma. J Am Chem Soc, 2010, 132: 7976-7981

16 Henke J I, Goergen D, Zheng J, et al. microRNA-122 stimulates translation of hepatitis C virus RNA. EMBO J, 2008, 27: 3300-3310

17 Lanford R E, Hildebrandt-Eriksen E S, Petri A, et al. Therapeutic silencing of microRNA-122 in primates with chronic hepatitis $\mathrm{C}$ virus infection. Science, 2010, 327: 198-201

18 Wilson J A, Zhang C, Huys A, et al. Human Ago2 is required for efficient microRNA 122 regulation of hepatitis $\mathrm{C}$ virus RNA accumulation and translation. J Virol, 2011, 85: 2342-2350

19 Yang N, Cao Y, Han P, et al. Tools for investigation of the RNA endonuclease activity of mammalian Argonaute2 protein. Anal Chem, 2012, 84: 2492-2497

20 Roberts A P, Lewis A P, Jopling C L. miR-122 activates hepatitis C virus translation by a specialized mechanism requiring particular RNA components. Nucleic Acids Res, 2011, 39: 7716-7729

21 Jopling C L, Yi M, Lancaster A M, et al. Modulation of hepatitis C virus RNA abundance by a liver-specific MicroRNA. Science, 2005, 309: 1577-1581

22 Yin $\mathrm{H}$, Zhou Y, Zhang H, et al. Electrochemical determination of microRNA-21 based on graphene, LNA integrated molecular beacon, AuNPs and biotin multifunctional bio bar codes and enzymatic assay system. Biosens Bioelectron, 2012, 33: 247-253

23 Huntzinger E, Izaurralde E. Gene silencing by microRNAs: contributions of translational repression and mRNA decay. Nat Rev Genet, 2011, 12: 99-110

24 Hun X, Wang Z P. L-Argininamide biosensor based on S1 nuclease hydrolysis signal amplification. Microchim Acta, 2012, 176: 209-216

Open Access This article is distributed under the terms of the Creative Commons Attribution License which permits any use, distribution, and reproduction in any medium, provided the original author(s) and source are credited. 